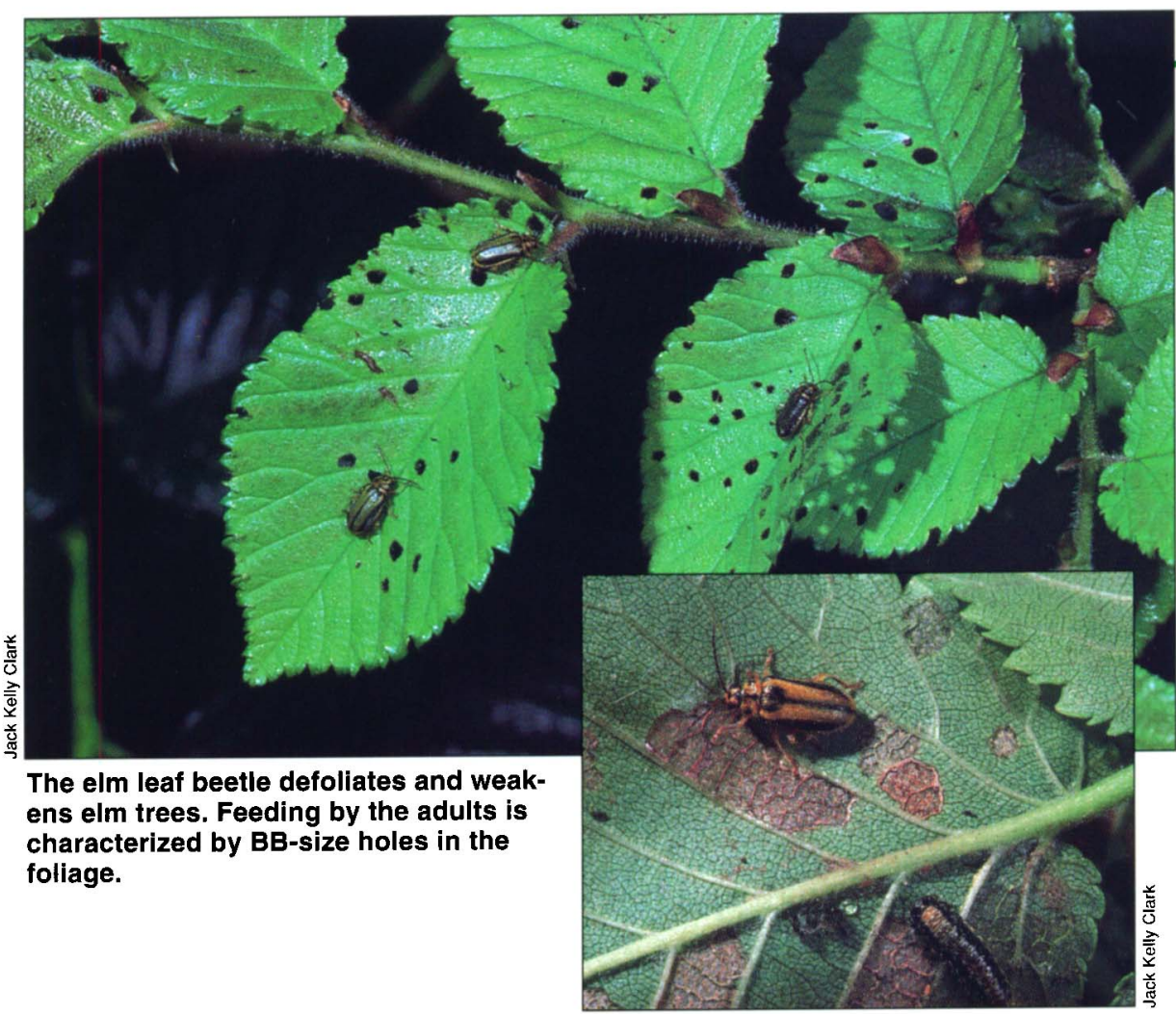

\section{IPM helps control elm leaf beetle}

\author{
Donald L. Dahlsten $\quad \square \quad$ David L. Rowney $\sqsupset$ Andrew B. Lawson
}

The elm leaf beetle, first discovered in California in the 1920s, quickly became one of the state's major urban tree pests. In the past 15 years, monitoring methods have become integral to the design of the Integrated Pest Management program for the elm leaf beetle (ELB). A sampling protocol has been developed that can successfully predict $E L B$ damage based on the presence or absence of egg clusters. $A$ monitoring program based on this sampling technique may allow managers to direct control efforts to only those trees requiring treatment, thus avoiding unnecessary environmental and economic costs. Chemical insecticides are still a temporary solution to the problem, but increasing concern for human and environmental health has stimulated the pursuit of nonchemical approaches. Releases of egg parasitoids have been largely unsuccessful over the past 12 years. An effort is currently under way in Sacramento to improve the Integrated Pest Management program based on monitoring, spot treatments with injected chemical insecticides, foliar application of Bacillus thuringiensis and the release of a new strain of egg parasitoid from Granada, Spain.

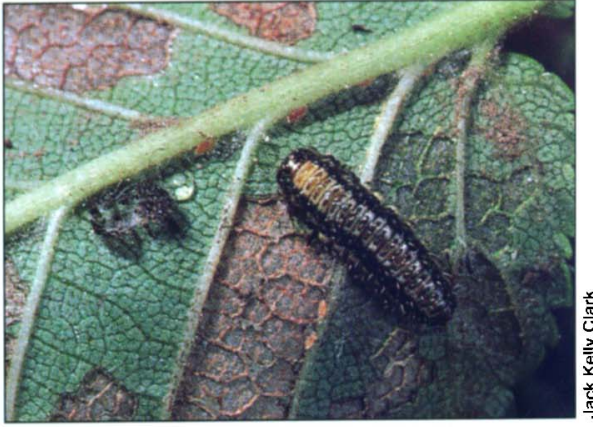

Larval feeding skeletonizes the foliage, often causing the leaves to drop.

The elm leaf beetle was accidentally introduced into the eastern United States from Europe in the 1830s. The beetle was not found in California until the 1920s, but it can now be found almost anywhere there are elms. The horticultural industry has undoubtedly been responsible for the movement of the beetles, and as modes of transportation have improved so has the ability of the beetles to spread. The beetle, which defoliates and weakens trees, can now be found in such distant places as Argentina and Australia.

There are no native elms in California, but it is estimated that 2.5 million elms have been planted in the state. The most common elms planted are English (Ulmus procera), Siberian ( $U$. pumila), Chinese (U. parvaflora) and American (U. americana). English elm is the most susceptible to elm leaf beetle feeding and the Siberian elm is the second most susceptible (Luck and Scriven 1979). The elm leaf beetle (ELB), Xanthogaleruca luteola, is the most important pest of elms in California; it is ranked as the second most important urban tree pest in the western United States and third nationwide (Wu et al. 1991).

\section{Life cycle and damage}

The beetles overwinter as adults in sheltered places such as woodpiles, garages, attics and so on. Overwintering beetles in buildings are a nuisance and a cause of many calls to pest control applicators and UC Cooperative Extension personnel. As the elm buds burst and the foliage begins to develop in the spring, the adults emerge from 
their hiding places and feed on the foliage for 1 to 2 weeks before starting to lay eggs. Adult feeding is characterized by circular BB-size holes in the foliage. The oblong yellow eggs are laid in clusters of 15 to 20 . The larvae, which are the most damaging stage, develop through three instars. Larval feeding skeletonizes the foliage, often causing the leaves to drop. When ready to pupate, the larvae crawl into holes in the trunk of the tree, in limb crotches, beneath loose bark or commonly at the base of the tree, where they gather in large numbers. Depending on the climate, there can be one to three generations per year in the northern part of the state and even more in Southern California. The larval stage is usually the focal point for chemical control efforts.

The primary impact of defoliation is the loss of shade during the summer months and the cost of control. Defoliation, even annually, does not normally kill trees, but it does weaken them, making them more susceptible to other mortality agents. To prevent defoliation, various agencies and individuals have been willing to spend thousands of dollars per year. The responsibility for elm pest management falls on city government for streetside trees, park managers for park trees, and homeowners for trees in yards.

\section{Monitoring program}

From 1984 to 1993, we developed a user-friendly sampling technique (fig. 1). During this period we sampled more than 200 trees in more than 25 cities in Central and Northern California. Because English elm is the most susceptible elm, we have focused most of our efforts on this species.

The optimal time to sample and treat ELB is best determined by monitoring heat accumulation, expressed in degree-days (DD). We sampled eggs, three larval instars, and adults throughout the season at numerous sites and years, while monitoring DD above the ELB developmental threshold of $50^{\circ} \mathrm{F}\left(11^{\circ} \mathrm{C}\right)$, starting on March 1 at each site. We recorded accumulated DD at the time of peak density of each life stage, and calculated the mean DD for each stage for all sites and years. These values can be used to predict when insects at a particular stage will be most numerous at a site. Weather data for DD was obtained from three sources: (1) minimum/maximum temperatures published in daily newspapers; (2) on-site temperature recorders or Biophenometers, which accumulate and display DD directly; and (3) data from nearby weather stations connected to UC's IPM computer system. Computer programs from the UC IPM system were used to calculate DD when only minimum/maximum data was available.

A 1-foot $(30-\mathrm{cm})$ elm branch terminal is the sampling unit on which the monitoring system is based. Mean ELB

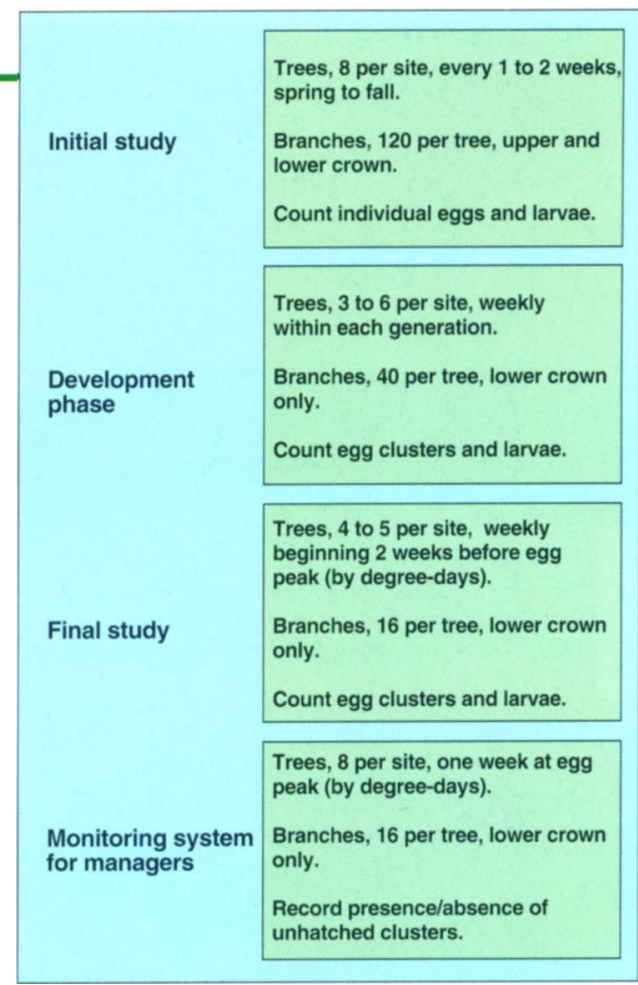

Fig. 1. Development of elm leaf beetle sampling.

TABLE 1. Suggested sample size for elm leaf beetle egg cluster monitoring on English elm in stands of different sizes. Eight locations per tree are sampled: north, east, south and west; inner

\begin{tabular}{lccccc}
\multicolumn{7}{c}{ and outer crown } \\
\hline \hline $\begin{array}{c}\text { Total } \\
\text { trees }\end{array}$ & $\begin{array}{c}\text { Sample } \\
\text { trees }\end{array}$ & $\begin{array}{c}\text { Samples/ } \\
\text { tree }\end{array}$ & $\begin{array}{c}\text { Samples/ } \\
\text { segment }\end{array}$ & $\begin{array}{c}\text { Total } \\
\text { samples }\end{array}$ & Trees \\
\hline
\end{tabular}

\begin{tabular}{|c|c|c|c|c|c|}
\hline trees & trees & tree & segment & samples & Trees \\
\hline & & & & & $\%$ \\
\hline 3 & 3 & 40 & 5 & 120 & 100 \\
\hline 4 & 4 & 32 & 4 & 128 & 100 \\
\hline 5 & 5 & 32 & 4 & 160 & 100 \\
\hline 6 & 6 & 24 & 3 & 144 & 100 \\
\hline 7 & 6 & 24 & 3 & 144 & 86 \\
\hline 8 & 7 & 24 & 3 & 168 & 88 \\
\hline 9 & 8 & 16 & 2 & 128 & 89 \\
\hline 10 & 8 & 16 & 2 & 128 & 80 \\
\hline 11 & 8 & 16 & 2 & 128 & 73 \\
\hline 12 & 8 & 16 & 2 & 128 & 67 \\
\hline 13 & 8 & 16 & 2 & 128 & 62 \\
\hline 14 & 8 & 16 & 2 & 128 & 57 \\
\hline 15 & 8 & 16 & 2 & 128 & 53 \\
\hline 16 & 9 & 16 & 2 & 144 & 56 \\
\hline 17 & 9 & 16 & 2 & 144 & 53 \\
\hline 18 & 9 & 16 & 2 & 144 & 50 \\
\hline 19 & 9 & 16 & 2 & 144 & 47 \\
\hline 20 & 9 & 16 & 2 & 144 & 45 \\
\hline 21 & 9 & 16 & 2 & 144 & 43 \\
\hline 22 & 10 & 16 & 2 & 160 & 45 \\
\hline 23 & 10 & 16 & 2 & 160 & 43 \\
\hline 24 & 10 & 16 & 2 & 160 & 42 \\
\hline 25 & 10 & 16 & 2 & 160 & 40 \\
\hline 26 & 10 & 16 & 2 & 160 & 38 \\
\hline 27 & 10 & 16 & 2 & 160 & 37 \\
\hline 28 & 10 & 16 & 2 & 160 & 36 \\
\hline 29 & 10 & 16 & 2 & 160 & 34 \\
\hline 30 & 10 & 16 & 2 & 160 & 33 \\
\hline 40 & 12 & 16 & 2 & 192 & 30 \\
\hline 50 & 15 & 16 & 2 & 240 & 30 \\
\hline 60 & 15 & 16 & 2 & 240 & 25 \\
\hline
\end{tabular}

Criteria: (1) Minimum of 128 branches should be sampled. (2) Minimum of $25 \%$ of the trees should be sampled. 


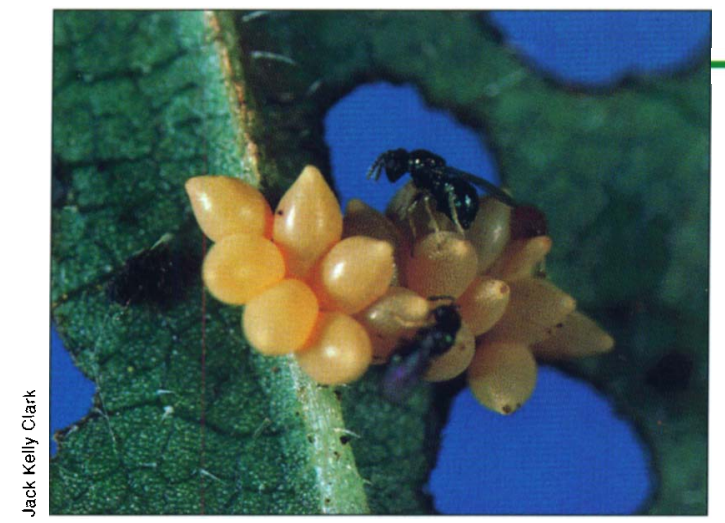

Oomyzus gallerucae may parasitize $50 \%$ to $90 \%$ of an egg cluster. In addition, these small wasps host-feed on other eggs, essentially destroying the entire egg cluster.

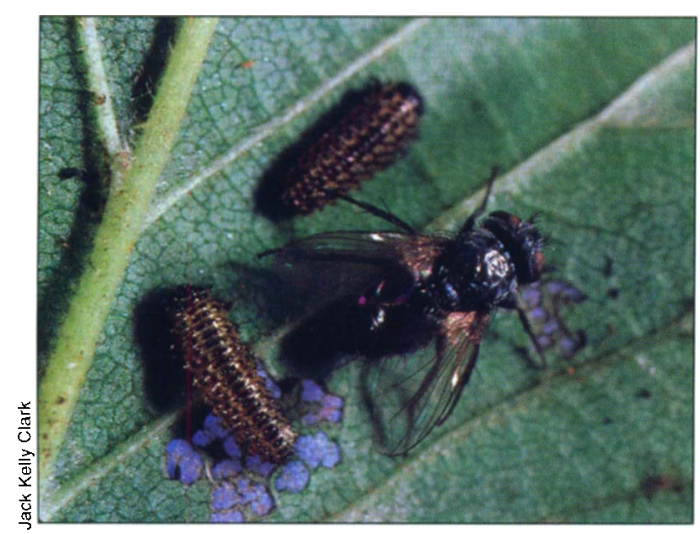

Erynniopsis antennata is one of two parasitoids released in California in the 1930s. ELB parasitism can exceed $40 \%$.

viable (unhatched) egg-cluster density was used for damage prediction initially because of convenience, and sampling clusters allows time to make treatment decisions before the damaging larval stage occurs. We have determined that simply recording the presence or absence of viable egg clusters on each sample unit provides good damage prediction. Because we found significant differences in egg density between cardinal directions but not between the upper and lower crown, branches are now taken from the more easily sampled lower crown at eight locations around the tree. Sampling locations are north, east, south and west, in both the inner crown (from trunk halfway to drip line) and the outer crown.

We developed a scheme that offers a good compromise between sampling effort and precision for sites of different sizes. This scheme gives the number of trees to be sampled and the number of branches to be examined per tree, depending on the site (table 1). Trees for sampling should initially be chosen randomly, and the same trees should be sampled on each later date. Large sites may be divided into sections and trees chosen randomly within those sections so that samples pick up any spatial variation in ELB density. For example, a 60-tree site could be divided into three 20 -tree sections and 5 sample trees chosen per section.

We also developed a rating system to determine foliage damage levels by ELB. We rate the combined adult and larval damage on each 1 -foot $(30-\mathrm{cm})$ branch terminal on a scale of 0 to 10 , where 1 equals $10 \%$ and 10 equals $100 \%$ defoliation. Damage on a foliage sample is rated by comparing it to a visual standard, which shows examples of leaves with each damage rating. Managers may want to rate damage using this method, or they may use the less labor-intensive and less accurate method of visually rating the whole tree from 0 to 10 to estimate damage from each ELB generation. For sites with a single ELB generation, that generation's damage is measured at the end of the season in the fall. For sites with multiple generations, damage is rated for each generation; damage at the peak of egg levels (or at the end of the season for the last generation), minus damage at the prior egg peak, equals the damage caused by the previous generation's larvae and adults.

Because there were no previously established treatment thresholds, we chose a damage rating of 4 as our threshold, based on our experience with homeowners and tree managers. In the first generation, when sampling at the peak of egg cluster density, if $45 \%$ or fewer samples have viable egg clusters present, then the damage at the end of that generation will be in the acceptable range (damage rating of 4 or less), with a probability of error of $10 \%$. In the second generation, the maximum percentage of branches infested for acceptable damage is about $30 \%$.

\section{Vary by year, generation, site}

We originally hoped to predict ELB damage and the need for control throughout the season by sampling viable egg clusters only in the first generation. However, first-generation sampling did not always predict season-long damage adequately because of differences in population patterns between generations, years and sites. For instance, the damage in 4 years of sampling at Cloverdale, Sonoma County (fig. 2) was well above the acceptable level at season's end, but it would have been difficult to predict this result from either the very low first-generation samples in 1988 or the moderate egg level for the first generation of 1989. At this site, in some years the ELB population level was low in the first generation and high in the second, and sometimes the opposite. At another site, Santa Margarita in San Luis Obispo County, first generations were mostly high in the 4 years we sampled $(1989,1990$, 1991 and 1993), and after the first generation, damage was above $40 \%$ for 3 of the 4 years. Second generations were relatively low for all years except 1989, when beetle emergence coincided with a heavy reflush of new foliage. A third site, St. Helena, Napa County, had relatively light damage from ELB first generation in 1986, 1988 and 1990 , and much heavier (>90\%) damage in 1987 and 1989. All years except 1987 and 1989 had heavy secondgeneration cluster density, which caused significant additional damage by season's end.

In our latest study area in Sacramento, only 2 of 4 sites had ELB populations high enough to warrant treatment in any generation in 1995.

Significant populations occurred in 1996 in only 2 of 11 sites, and in 1997 in only 3 of 10 sites. One site (the city cemetery) had consistently high first and second generations, based on peak of presence of egg clusters, over the past 3 years. In 1996, the third generation had heavy parasitization (fig. 3). This patchy distribution emphasizes the need for control programs 
based on monitoring so that control efforts can be directed to these "hot spots" of ELB activity.

Because of population variation across the various ELB generations just discussed, each generation needs to be monitored. We recommend weekly presence/absence egg cluster monitoring starting about 50 DD before the predicted egg peak for each generation (for example, at 233 DD for generation one and 903 DD for generation two) and continuing for 1 or 2 more weeks (DD calculated in degrees Centigrade).

Monitoring is key to an integrated pest management program for ELB because it gives advance notice of when treatments are needed or when nothing should be done. Although chemical insecticides - either by foliar application or injection - are very effective, they have been used in many instances when ELB populations were not dense enough to cause significant damage. The monitoring system is not only important for timing control methods but also for determining which areas or trees should be treated and for which generation. Recent interest in systemic insecticides, which must be applied well in advance of the first generation of beetles, defeats the purpose of monitoring and often results in control costs when none are necessary. The monitoring system alone, therefore, not only reduces the amount of chemicals used, it also avoids expenditures for controls when they are not necessary.

\section{Biological control}

For the last 15 years, the focus in our laboratory has been on classical biological control by the introduction of a small eulophid egg parasitoid, Oomyzus gallerucae. These small wasps may parasitize $50 \%$ to $90 \%$ of the eggs in a cluster in addition to host-feeding on other eggs in the cluster, essentially destroying the entire egg cluster. The first releases of this parasitoid in California were made from 1932 to 1935 , but there was little in the way of evaluation. A strain from Iran was released at several locations in the mid-1970s.

Since our program began in 1984, we have released approximately 400,000 O. gallerucae in 28 locations in California, representing at least seven strains from several European sources (fig. 4). The parasitoids collected in Ohio and Stockton were believed to be originally from France and Morocco, respectively. In Sacramento over the past 2 years, we have focused on releases of a strain from Granada, Spain.

Studies with the egg parasitoid have been frustrating. Parasitism during the year of release may be as high as $95 \%$ of ELB eggs, but the parasitoids apparently do not overwinter well in California; they are normally not recovered the year after release.

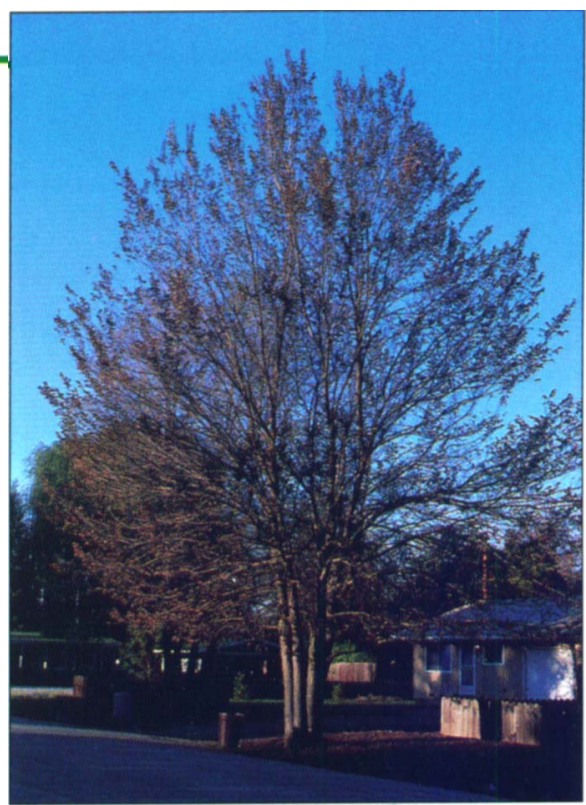

Elm leaf beetles completely defoliated this tree in San Luis Obispo County.

Occasionally, however, parasitoids have been recovered in years subsequent to field release, indicating that a small number may be surviving, but not enough to significantly affect ELB levels. In laboratory studies, we have confirmed that a low percentage of parasitoids possess the longevity to successfully overwinter in our climate.

We still do not understand the difference between collection sites in Europe, where egg parasitoids can be collected regularly in the spring, and release sites in California. We do not know why the parasitoids apparently overwinter with ease in Europe but not in California, even though the climates of the two areas are very simi-

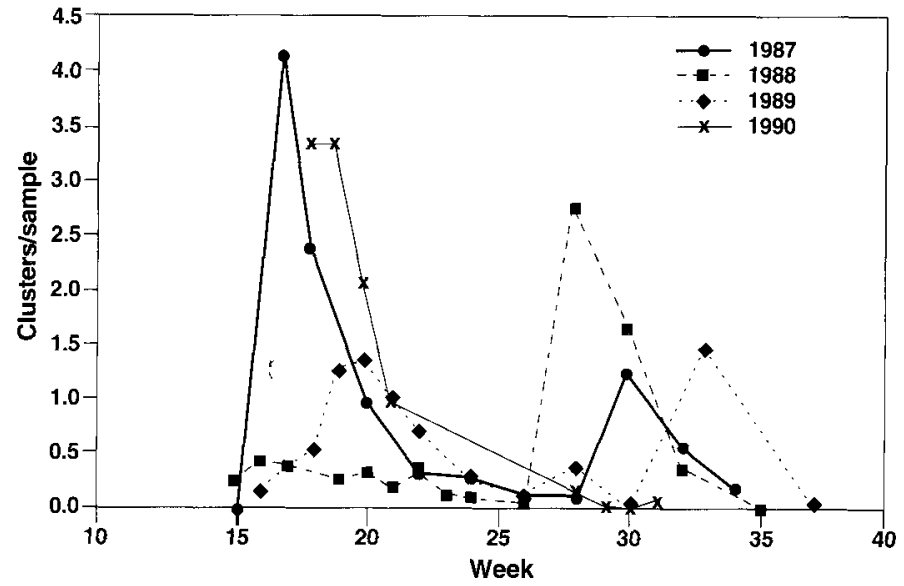

Fig. 2. Elm leaf beetle egg cluster weekly density during a 4-year period in Cloverdale.

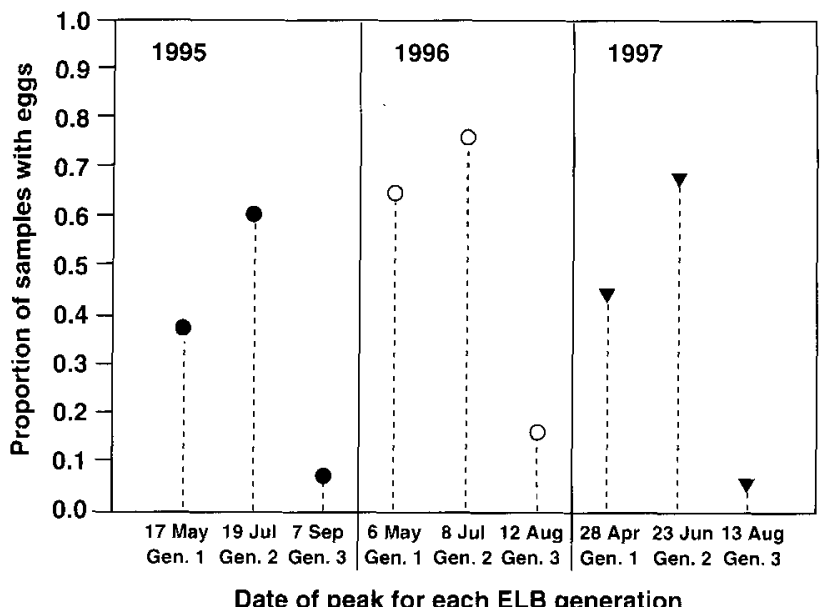

Date of peak for each ELB generation

Fig. 3. Elm leaf beetle egg cluster peaks during a 3-year period in the city cemetery, Sacramento. 


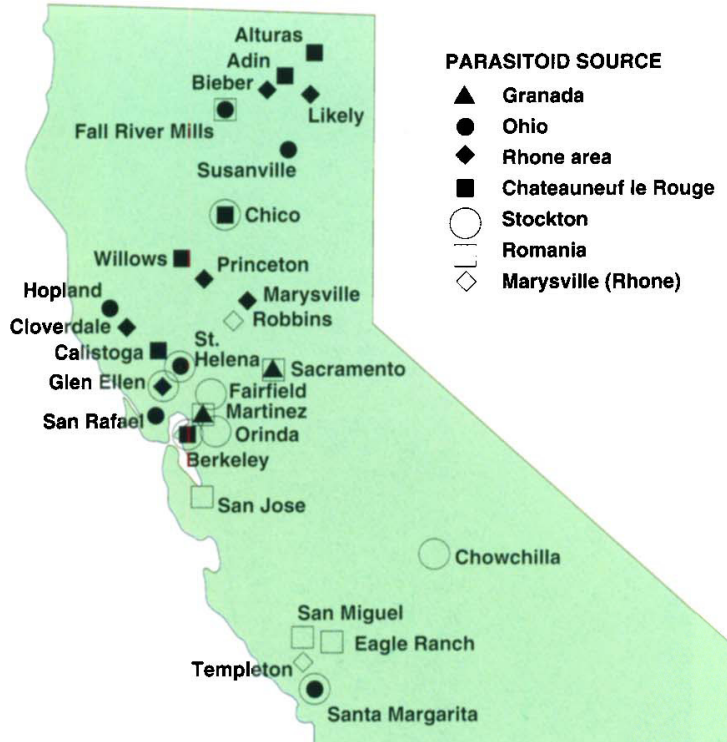

Fig. 4. Release sites since 1984 in Northern and Central California for different strains of the parasitoid Oomyzus gallerucae.

lar. We are currently working with the Granada strain in Sacramento, not only because there is a close climatic match, but also because this strain is known to regulate ELB populations in certain areas of Granada.

Because the parasitoids are effective within a season when they are present in significant numbers, it is possible to make inoculative releases of insectaryreared parasitoids in the spring. This would require a large-scale insectaryrearing program to be in operation over the winter, as well as a monitoring program to determine where and when parasitoids should be released. Another option would be to ship fieldcollected parasitoids from the Southern Hemisphere's fall season (in Argentina or Australia for instance), for release in the Northern Hemisphere's coincident spring season.

Two other parasitoids, Aprostocetus brevistigma and Erynniopsis antennata, were released in California in 1934 and 1938 respectively. We found the eulophid wasp A. brevistigma, a gregarious pupal parasitoid from the northeastern United States, at many of our study sites in the state, but it was never very abundant. Erynniopsis antennata is a tachinid fly that is an internal larval parasitoid that emerges from the ELB pupae or adult. First released in Stockton, it can now be found all over California. Parasitism can exceed $40 \%$ at some sample sites, and it can help to reduce ELB populations, but its efficacy is often reduced by a eulophid hyperparasite, Aprostocetus erynniae (Dreistadt and Dahlsten 1990). Erynniopsis may have potential in areas that are free of the hyperparasite, such as Argentina and Australia.

To complement our biological control program, we have worked with two other procedures that do not harm the egg parasitoids. The first is a $2 \%$ solution of carbaryl sprayed on infested elms as a 1.6-foot

(0.5-meter) band on the trunk, about 10 feet (about 3 meters) above the ground. It is not effective on the first ELB generation, because it acts after first-generation larval feeding has occurred. This procedure is effective in reducing damage to Siberian elm. With English elm, repeated annual treatments may be necessary before a significant effect, if any, is noted (Dreistadt et al. 1991).

The second procedure is the use of the San Diego strain of Bacillus thuringiensis $(\mathrm{Bt})$, which is specific to chrysomelid beetles. Two applications per generation, timed 1 week apart, at the first-instar larval peak, has produced good results at one location in Sacramento.

\section{Demonstration in Sacramento}

To see if an IPM program could be developed for ELB, we decided to focus on English elm, which suffers the most damage, in a large urban area with many elms. Sacramento has more elms (several thousand) than any other city in California, and currently has two organizations involved in their upkeep. The city government's Department of Neighborhood Services is responsible for controlling ELB in street trees and parks, and a nongovernment organization, the Sacramento Tree Foundation, has a "Save the Elms
Program"(STEP), which works with the public on elm problems. STEP has a volunteer force of more than 200 , dedicated to monitoring the elms of Sacramento for Dutch elm disease. In 1996, STEP incorporated some of our ELB monitoring techniques into their training and outreach programs in the neighborhoods.

In 1996, the three agencies (City of Sacramento Department of Neighborhood Services, STEP and UC) received a grant from the California Department of Pesticide Regulation to implement the IPM program. Each of the agencies was therefore able to hire extra help to implement our monitoring methods in Sacramento. In addition, the group began to look at the development of new methods for large urban areas, as well as to evaluate new and existing control methods.

We were successful in training city and STEP personnel to use the degreeday model and ELB monitoring techniques described earlier. Surveys in 1996 showed damage to be spotty, and efforts will be made in the future to identify these "hot spots" of high ELB activity so that control activities can be concentrated where they are most needed. In one of our study sites at the city cemetery, Bt sprayed twice in each of two generations reduced damage to acceptable levels in treated plots in comparison with untreated plots. 'Granada' strain parasitoids released in the first generation controlled the third generation in spray plot trees. As with our previous experience, egg parasitism in 1997 was not detected.

It appears from our initial effort that the monitoring experiment is working. If only the areas with significant numbers of beetles are treated, even by the conventional chemicalinsecticide injection method the city uses now, monitoring will result in much less insecticide in the environment and considerable savings to the city.

An important part of an IPM program in the urban environment is involvement of the public. In Sacramento, residents in study sites were contacted personally and given infor- 
mation on ELB, the goals of the program and specifics on the treatments in their area. STEP also made presentations to neighborhood associations and displayed an information table at a popular outdoor market throughout the summer. Through community education and outreach, the cooperation of city agencies, good monitoring and the development of new strategies to control elm leaf beetles in "hot spots," the IPM program for Sacramento is being developed and should be fully implemented within several years.

D.L. Dahlsten is Professor and Associate Dean, D.L. Rowney is Biostatistician and A.B. Lawson is Graduate Student Researcher, Center for Biological Control, Division of Insect Biology, College of Natural Resources, UC Berkeley.

The authors thank the many individuals and agencies that have assisted in the development of this program over the years, and particularly Steve Dreistadt, UC Davis, UC/IPM Project; Beverly Gingg, San Luis Obispo; Anne Fenkner and Barbara Gemmill, Sacramento Tree Foundation, Sacramento; and Martin Fitch and Bob Hughes, Department of Neighborhood Services, Sacramento.

They thank the UC/IPM Project, UC Davis and the Slosson Foundation for funding earlier aspects of the study, and the California Department of Pesticide Regulation Grant \#95-0254 for funding the current program in Sacramento.

\section{References}

Dreistadt SH, Dahisten DL. 1990. Distribution and abundance of Eurnniopsis antennata [Dipt: Tachinidae] and Tetrastichus brevistigma [Hym.: Eulophidae], two introduced elm leaf beetle parasitoids in northern California. Entomphaga 35(4):527-36.

Dreistadt SH, Dahlsten DL, Rowney DL, et al. 1991. Treatment of destructive elm leaf beetle should be timed by temperature. $\mathrm{Cal}$ $\mathrm{Ag} \mathrm{45(2):23-5.}$

Luck RF, Scriven GT. 1979. The elm leaf beetle, Pyrrhalta luteola, in southern California: Its host preference and host impact. Environmental Entomology 8:307-13.

Wu Z, Jamieson S, Kielbaso J. 1991. Urban forest pest management. J Arboriculture 17(6).
Invisible invaders . . .

\section{Insect-transmitted viruses threaten agriculture}

\author{
Robert L. Gilbertson a Diane E. Ullman, first authors \\ Raquel Salati J Douglas P. Maxwell \\ Elizabeth E. Grafton-Cardwell 口 MaryLou Polek
}

The vast movement of people and agricultural products between distant geographical regions has created unprecedented opportunities for introducing plant viruses and the insects that carry them (vectors) to new areas. Outbreaks of new viruses may be favored in these agroecosystems by crop susceptibility, the presence of particular weeds and certain agricultural practices. In some cases, conditions in these ecosystems may be ideal for the emergence of altered plant viruses and new virus/vector relationships. This may result in the appearance of insect-transmitted plant viruses in crops and regions where they have not been seen before. Because plant viruses and their insect vectors are intimately linked, the status of both must be considered in formulating strategies to prevent or slow their introduction, as well as to manage any invasions. To illustrate these points we highlight two situations that could threaten California agriculture. First, a devastating plant virus, tomato yellow leaf curl geminivirus, is not present in California, but an insect (the silverleaf whitefly) that transmits it is present. Second, the brown citrus aphid is not present in California, but a citrus virus (citrus tristeza closterovirus) that this insect efficiently spreads, is present.
Despite technological advances leading to tremendous yield increases for many crops, modern agricultural production continues to face pest threats, among them insects, plant pathogens, and weeds. Often growers are faced with multiple pests, which exacerbates crop damage and complicates management strategies. A dramatic example of how two types of pests "team up" to cause major problems for California agricultural production is the case of plant viruses and their insect vectors.

Plant viruses are foreign genetic elements that take over a plant's cellular machinery and use it to produce their own genetic material and proteins. This has dire consequences for the plant, altering many normal plant functions such as cell division and photosynthesis, thus resulting in disease. While symptoms of virus infection vary depending on the particular virus and plant, they generally involve stunted and distorted growth, changes in leaf coloration and shape, and poor flower and/or fruit yield and quality. Most plant viruses are not stable outside of living plant cells and so need a way to spread from infected plants to uninfected plants. Plant-feeding insects are ideal agents for spreading plant viruses because of their high rates of reproduction, dispersal abilities, and obligate use of particular plants as food. Indeed, intricate relationships have coevolved among insects, viruses and the plant hosts they share, resulting in remarkably efficient spread of viruses from plant to plant. 